\title{
Signal Processing Method for Vehicle Wheel Force Sensor using DSP
}

\author{
Jinsung Lee, Kyuwon Jeong \\ Chungbuk National University \\ Chungdae-ro 1, Seowon-Gu, Cheongju, Chungbuk, Korea \\ jins1207@naver.com; jeong@ chungbuk.ac.kr
}

\section{Extended Abstract}

A vehicle wheel force sensor is used for measuring the forces and moments applied on the wheel, which is installed on between the vehicle wheel and power transmission axle [1-4]. The sensor must be very rugged and the shape is of pan cake type similar to the vehicle wheel. In order to obtain the measuring signals there are many strain gauges attached on the bridge beams. Conventional load cell used in weighing scale is operated in static conditions where the very narrow dynamic range is acceptable. However, since a vehicle runs very fast, the dynamic rage required for the wheel force sensor should be wide in very high frequency and the signal processing should be done in very short time. Furthermore, around the engine room it is noisy because of the engine.

In this paper a signal processing circuit and algorithm are developed and tested for the sensor. The analogue signal amplifier circuit was designed theoretically and in simulation in order to remove the noise but have uniform gain over the working frequency range [5-8]. Obtaining the Bode diagram the performance is confirmed by a series of experiments. Because the wheel rotates continuously during the vehicle runs the coordinate of the sensor is changed according to the wheel rotation. Since vehicle designer, however, wants to know the reaction forces in the stationary coordinate, the obtained strain gage signals have to be converted to the forces in the coordinate. So, the signal processing algorithm and conversion formula are implemented using digital signal processor (DSP) and the processed output signal is transmitted to the data gathering computer via wired or wireless communication line $[9,10]$.

\section{References}

[1] H. Youshikawa and Kakogawa, "Device for measuring components of force and moment applied to vehicle tire," U.S. Patent 4748 844, June 7, 1988.

[2] T. Ichige, "Rotary type component force measuring device," U.S. Patent US 2006/0037409 A1, Feb. $23,2006$.

[3] L. Feng and G. Lin, "Inertia coupling analysis of a self-decoupled wheel force transducer under multi-axis acceleration fields," School of Instrument Science and Engineering, Southeast Univ, Nanjing, China, 2015.

[4] M. G. Kim and J. W. Joo, "Structural design and evaluation of six-component wheel dynamometer", Journal of The Korea Society of Mechanical Engineers, vol. 40, no. 1, pp. 53-63, 2016.

[5] D. F. Stout and M. Kaufman, Handbook of Operational Amplifier Circuit Design. pp. 8.1-8.8, 1982.

[6] K. Ogata, Modern Control Engineering. pp. 639-648, 2001.

[7] J. C. Baek, TMS320F28x CPU Handbook, pp. 1.3-1.48, 2014.

[8] J. K. Lee, "An Implementation of adaptive noise canceller using instantaneous signal to noise ratio with DSP processor," The Journal of Korea Institute of Signal Processing and System, vol. 10, no. 3, pp. 158-163, 2009.

[9] S. H. Kim, "ZigBee service gateway enabling dynamic reconfiguration," The Journal of the KICS, vol. 32, no. 10B, pp. 644-654, 2007.

[10] H. H. Choi, "An transmission time allocation Scheme in ZigBee Network," Journal of the Korea society of computer and information, vol. 16. no. 4, pp. 119-126, 2011. 